\title{
Caridad pastoral como caridad filial en el sacerdocio ministerial: don de sí a la luz de la vida y actuación del Hijo Pastoral Charity as Filial Charity in Ministerial Priesthood: Self-giving in the Light of Son's Life and Action
}

\author{
JuAn MANuel CABIEDAs TeJero
}

Universidad Pontificia de México

ORCiD: 0000-0002-3738-5149 | jmkbite@icloud.com

Fecha de recepción: 7/7/2021

Fecha de aceptación: 1/10/2021

https://doi.org/10.52039/seminarios.v66vi229.467

RESUMEN: «Caridad pastoral como caridad filial en el sacerdocio ministerial» es el título de una reflexión desarrollada en dos estudios sucesivos. Considerando la sensibilidad cristológica de la Carta a los Hebreos, el presente artículo se interesa por mostrar cómo el título «Hijo de Dios», a la luz de la radicalidad de la obediencia de Jesús a Dios Padre y la unicidad de su donación al otro, conduce a la primera Iglesia a reconocer la condición sacerdotal de Cristo como exponente de aquel estilo de mediación salvífica que marca el camino de todo discípulo hacia la plena realización de su identidad personal en relación con Dios Padre. En continuidad con este punto de partida, en un segundo trabajo será posible explorar cómo esa «sinergia sacerdotal» entre identidad y donación que conforma germinalmente la vida cristiana, define a su vez el carácter relacional que funda el sentido y orienta la misión del sacerdocio ministerial en la Iglesia.

PALABRAS CLAVE: Carta a los Hebreos, identidad personal, Hijo de Dios, vocación cristiana, sacerdocio cristiano.

ABSTRACT: «Pastoral Charity as Filial Charity in Ministerial Priesthood» is the title of a study developed in two steps. Considering the Christological sensitivity of the Letter to the Hebrews, this article attempts to show how the title «Son of God», in the light of the radical nature of Jesus' obedience to God the Father, and the uniqueness of his self-donation to others, leads the early Church to recognize Christ's priestly condition as an expression of that style of salvific mediation that sets out the path of every disciple towards the full realization of his personal identity in relation to God the Father. In continuity with this starting point, in a second study we will explore how this «priestly synergy» between identity and self-giving, which seminally shapes Christian life, defines in turn the relational character that establishes the meaning and orients the mission of ministerial priesthood in the Church.

KEYwORds: Epistle to the Hebrews, Personal identity, Son of God, Christian vocation, Christian Priesthood. 


\section{INTRODUCCIÓN}

\section{a) Proyecto y objetivo}

Bajo el título «Caridad pastoral como caridad filial en el sacerdocio ministerial» presento una única reflexión desarrollada en dos pasos sucesivos. Volviendo sobre la sensibilidad cristológica de la Carta a los Hebreos, este primer estudio indaga cómo «la vida filial, que en Él [Cristo] se muestra, manifiesta la altura de la vocación humana» ${ }^{1} \mathrm{y}$, en concreto, actúa como el fundamento que motiva la existencia cristiana como vivencia y ejercicio de filiación; es decir, como espacio de mediación entre la potencia relacional que determina la identidad personal del hombre y la donación gratuita de Dios Padre a la misma en la persona del Hijo. En continuidad con este punto de partida, en un segundo trabajo me propongo explorar esa 'sinergia sacerdotal' entre identidad y donación que conforma la vida del discípulo, como referente de la entrega de sí que funda el sentido y orienta la misión del sacerdocio ministerial en la Iglesia. En efecto, tendremos oportunidad de reflexionar sobre la persona del sacerdote como hijo del Padre y discípulo de Cristo que responde en el seno de la Iglesia a una vocación pastoral («para ser pescador de hombres»), unido sacramentalmente a la vida y acción del Hijo a través del Espíritu.

Al tomar como horizonte de referencia del sacerdocio (común y ministerial) el signo antropológico de la donación de sí, mi intención no es directamente la de contrarrestar la tentación de la auto-referencialidad que, como señala repetidamente el Papa Francisco, sigue minando hoy la fidelidad del creyente y sofoca la pasión de todo agente pastoral, también de obispos y sacerdotes (con su coda de mundanidad espiritual y clericalismo sofisticado $)^{2}$. Propongo, sobre todo, volver sobre la forma 'crística' de la filiación en cuanto fondo teológico esencial que nutre la identidad sacerdotal de todo bautizado $^{3}$-pues apunta al carácter esencialmente relacional de su condición humana creada «a imagen y semejanza de Dios» (Gn 1, 26)- y, por ende, alienta en la Iglesia la especificidad del sacerdocio ministerial como signo de

1. Comisión Teológica Internacional, La reciprocidad entre fe y sacramentos en la economía sacramental, n. $25<\mathrm{https}$ //www.vatican.va/roman_curia/congregations/cfaith/cti documents/rc_cti_20200303_reciprocita-fede-sacramenti_sp.html $>$. [Consulta: 1 jul. 2021]

2. Francisco, Evangelii gaudium, n. 8, 93-97, 102: AAS 105 (2013) 1022. 1059-1061. 1062-1063.

3. M. Tenace, «La vocazione dell'uomo nuovo. Il senso della vita nuova accolta nel battesimo», en: P. Martinelli (a cura di), Custodi dello Stupore. La vita consacrata: Vangelo, profezia e speranza, Milano 2017, 221-240; K. Koch, La Iglesia de Dios. Comunión en el misterio de la fe, Santander 2015, 101-117. 
una vida filial en profunda comunión con el misterio y el ministerio del Hijo; en suma, como el sacramento de una llamada a ser totalmente para el Padre en sus hijos (y no de una mera función que demanda la comunidad cristiana $)^{4}$. En verdad, es la condición crístico-filial del bautizado la que ilumina la razón más honda que tiene éste para asumir una consagración específica al Reino de Dios que contribuye a activar en su persona toda el sentido y la eficacia de aquella identidad primera del ser personal que, en comunión con el Dios y Padre de Jesucristo, se puede llamar con toda propiedad relación: verdadero carácter indeleble del ser personal ${ }^{5}$.

\section{b) Marco: la persona del Hijo y la identidad de los hijos}

En el ámbito de lo que podríamos llamar la antropología de la vida cotidiana, la pregunta por la identidad sigue estando dominada hoy -en práctica continuidad con el sentir de la modernidad-por el punto de vista de la auto-experencia. De modo que, siendo en rigor el interrogante «¿quién soy yo?» el que rige el sentido de la conciencia de sí, en la medida en que este interrogante tiende a permanecer concentrado en la figura del sujeto en sí-concebido como centro autónomo en su conciencia y su libertad-, y dado que el punto de vista del en sí ni agota ni posee el secreto de la verdadera unicidad que es distintiva del hombre en cuanto ser personal, la única respuesta que parece plausible a la cuestión «¿quién soy yo?» es la que se erige a lo sumo en clave de relación con un otro (sea el mundo o el resto de sujetos) que me

4. Aun con las debidas cautelas, Robert Scholtus plantea abiertamente en un breve análisis de los desafíos a los que se enfrenta hoy la formación sacerdotal, que el hecho de que en muchos candidatos al ministerio y una creciente porción del clero joven prevalezca una visión más bien funcional de la figura del sacerdote y su papel en una Iglesia oscurecida por una cultura cada vez más secularizada (visión que está en sintonía, entre otras cosas, con la cultura digital a la que pertenecen y su influencia en una asimilación positivista de la teología y la tradición de la Iglesia...), «no se debe tanto a razones teológicas cuanto a la resistencia a ser borrados de la escena social y quedar relegados incluso dentro de las comunidades cristianas». Lo cual implica que un objetivo decisivo de la formación del futuro sacerdote «apunta a que la entrada al sacerdocio se produzca a través de la puerta de la vocación [...] Esto es lo que da forma en el candidato al hombre interior capaz de responder a la llamada del Espíritu y conformar su vida con sabiduría y libertad»: R. Scholtus, «The Formation of Priests Today: Cultural and Social Challenges of Priestly Formation in Europe», Seminary Journal 19 (2013) 18-21. La última formulación de la Ratio Fundamentalis Institutionis Sacerdotalis. El don de la vocación presbiteral (8 de diciembre de 2016) propicia, sin lugar a dudas, un modelo eclesial de formación sacerdotal aun más atento al cultivo sincrónico de la identidad teológico-crística y los recursos personales del candidato al ministerio como hombre que está llamado a vivir y expresarse desde la interioridad para la comunión.

5. «En el comienzo está la relación: como categoría del ser, como disposición, como forma que busca llenarse, como modelo anímico. Es el a priori de la relación, el tú innato»: M. Buber, Yo y Tú y otros ensayos, Buenos Aires 2013, 2 ed., 29. 
represento en función de mi «autorrealización»: ya se trate, por ejemplo, de la contribución voluntaria que puedo prestar al equilibrio del entorno-ecosistema (del que me siento parte) o de la ayuda solidaria que puedo brindar al otro-sociedad en sus necesidades (por las que me siento afectado) y expectativas (en las que me siento incluído).

En cambio, podría decirse que la formulación judeo-cristiana de la pregunta antropológica por la identidad es auténticamente post-moderna, pues la auto-experiencia subjetiva no radica en una auto-representación del otro como objeto de mi realización, sino fundamentalmente en mi pertenencia originaria e interiormente significativa a una comunión (Gn 1, 26: «Hagamos al hombre a nuestra imagen y semejanza») con vocación de plenitud (Jn 17, 21: «para que todos sean uno, como tú, Padre, en mí, y yo en ti, que ellos también sean uno en nosotros») ${ }^{7}$. Es decir, realmente yo soy (primera persona) fruto de una presencia, de un don $y$, en suma, de otro que me precede ${ }^{8} y$, al mismo tiempo, es tú para mí mismo (segunda persona) ${ }^{9}$. De manera que el

6. Crítico con este orden de la identidad, Charles Taylor afirma que «la normal comprensión de la autorrealización presupone que algunas cosas son importantes más allá del yo, que existen algunos bienes y afanes cuyo fomento tiene significación y que, por consiguiente, pueden aportar la significación que requiere una vida plena. Un subjetivismo total y plenamente consciente tendería hacia la vacuidad: nada contaría como realización en un mundo en que literalmente nada fuera importante aparte de la autorrealización»: Ch. Taylor, Las fuentes del yo. La construcción de la identidad moderna, Barcelona 2006, 685.

7. En efecto, sintetizando la historia de la salvación, el Concilio Vaticano II prolonga la afirmación de la creación del hombre «a imagen y semejanza de Dios» en el ruego cristológico, como confirmación de que es la «única creatura terrestre a la que Dios ha amado por sí misma» y, por tanto, «no puede encontrar su propia plenitud sino en la entrega sincera de sí misma a los demás»: Concilio Vaticano II, Const. Gaudium et spes, n. 24: AAS 58 (1966) 1045. Recordando esta misma expresión Juan Pablo II señala decididamente que «puede decirse que en estas palabras de la Constitución pastoral del Concilio se compendia toda la antropología cristiana: la teoría y la praxis, fundada en el evangelio, en la cual el hombre, descubriendo en sí mismo su pertenencia a Cristo, y la elevación a 'hijo de Dios', comprende mejor también su dignidad de hombre, precisamente porque es el sujeto del acercamiento y de la presencia de Dios, sujeto de la condescendencia divina en la que está contenida la perspectiva e incluso la raíz misma de la glorificación definitiva»: Juan Pablo II, Carta Enc. Dominum et vivificantem, n. 59: AAS 78 (1986) 886.

8. «Incluso nuestra propia verdad, la de nuestra conciencia personal, ante todo, nos ha sido dada» (Benedicto XVI, Carta Enc. Caritas in veritate, n. 34: AAS 101 (2009) 669.

9. Aunque no sea posible entrar aquí en una explicación detallada, me permito señalar que el tratamiento que hace la fenomenología clásica (Scheler, Husserl, Schutz) de la conformación de la auto-conciencia subjetiva - poniendo en evidencia la deficiente atención prestada por el modelo moderno de la autorrealización a la compleja dinámica afectiva que define la vida subjetiva- es uno de los frentes de investigación filosófica que mejor compañía presta hoy a la teología a la hora de actualizar la riqueza inscrita en la antropología judeo-cristiana y su visión de la alteridad que define la esencia del ser humano a la luz de su relación histórico-salvífica con el Dios que revela y actúa su identidad como unidad interpersonal. En efecto, una atención más cuidadosa al parámetro de la empatía en la relación humana básica yo-tú, 
evangelio alienta y activa sin dilación la respuesta a la interrogación «¿quién soy yo?» en el modo de la vocación: «ipara quién soy yo?» (Jn 15, 16: «soy yo quien os he elegido»). La referencia fundamental a cuya luz propone el evangelio la identidad del apóstol como vocación filial -o salida de un estricto sí mismo hacia un yo-nosotros- se encuentra en la relación de amor, mutua pertenencia y pleno reconocimiento, entre Dios como Padre y Jesús como su Hijo único y amado (cf. Mc 9, 7; Jn 10, 30). En esta experiencia cristológica que testimonia el evangelio y genera la vocación apostólica, esa relación Padre-Hijo se revela como inclusiva. Ciertamente Jesús se expresa y actúa como el Hijo porque su vida se nutre de una experiencia de donación sin parangón (cf. Jn 15, 9), propia de quien pertenece a la misma Vida del Padre (cf. Jn 14, 10); ahora bien, si como anota Ferdinand Ebner,

la afirmación del evangelio de Juan 14, 10: 'Yo estoy en el Padre, y el Padre en mí', no es una simple expresión del autosolipsismo interior de la experiencia mística de Dios, una expresión que la comprende e ilustra, sino que, al ser pronunciada por Cristo en la situación concreta de un discurso dirigido a otros, en la actualidad de una inmediatez y contemporaneidad espiritual, expone el carácter personal de aquel que habla ${ }^{10}$,

se puede decir que la lógica de la donación divina se re-vive en el plano de la humanidad de Jesús, el «nuevo Adán», asumida como instancia de ser capaz del otro como otro de sí. «El Hijo de Dios con su encarnación se ha unido, en cierto modo, con todo hombre» y «le descubre la sublimidad de su vocación» ${ }^{11}$; es decir, ilumina ese secreto central y decisivo de la identidad personal humana que consiste en ser desde el otro y para el otro. $\mathrm{O}$, dicho en clave evangélica, la posibilidad real de vivir como «hijo en el Hijo» $(\text { cf. Ef } 1,5)^{12}$.

muestra que la más definitiva conciencia de sí (yo-nosotros) no se da siendo uno-con-otro (Miteinandersein) sino uno-para-el-otro (Füreinandersein). Dicho de otro modo, la auto-experiencia es fruto, en su raíz, de una cierta auto-alienación: «Es necesario experimentar la mirada de los otros sobre uno mismo, ser consciente de ella como de uno mismo y verse a sí mismo a través de los ojos del otro, para poder experimentarme a mí mismo del mismo modo que yo hago experiencia de los demás. Cuando esto sucede, me hago consciente de mí mismo como uno de los otros o, dicho con más precisión, me hago consciente de mí mismo como uno de nosotros. Esta última auto-experiencia no reemplaza mi auto-conciencia pre-refleja: la complementa»: D. Zahavi, Self and Other. Exploring Subjectivity, Empathy, and Shame, Oxford 2014, 247.

10. F. Ebner, La realtà di Cristo, Brescia 2017, 91.

11. Concilio Vaticano II, Const. Gaudium et spes, n. 22: AAS 58 (1966) 1042.

12. Así expresa, por ejemplo, Ireneo de Lyon cómo podemos saber de nuestra filiación divina: «¿Cómo podríamos haber participado en la filiación adoptiva con respecto a Dios si no hubiéramos recibido, por medio del Hijo, la comunión con Dios? Y, ¿cómo habríamos 
Al recordar con afecto la impronta paterna en la propia vida, Manuel Vilas ha escrito que «el cristianismo, de una forma sencilla y elemental y no religiosa ni solemne, acaba por sugerirnos la inocente relación de un padre y un hijo» ${ }^{13}$. Todo el ser de la Iglesia (misterio de comunión) y su realización ministerial mana de esa relación originaria y única en su inocencia entre el Padre y su Hijo. Vivir del afecto transformador de esa relación es lo que permite a la Iglesia reconocer en todo tiempo la radical vocación de la historia del hombre como historia de salvación, como don del amor con el que el Padre ha amado al Hijo «antes de la fundación del mundo» $(\mathrm{Jn} 17,24)^{14}$. El fruto de ese eterno acto de amor-que es el nombre propio de la esencia divina: «Dios es amor» ( $1 \mathrm{Jn} 4,8.16$ )-, es el Espíritu que inspira a la Iglesia como sujeto que custodia el misterio inefable del Amor divino, empero no como espacio gnóstico, sino como comunidad de amor fraterno.

Dicho esto, y para tratar de dar cuenta de la trascendencia de esta dinámica familiar divina para la identidad del sacerdocio ministerial -expresión concreta de la sacramentalidad que es propia de toda la Iglesia como «instrumento de la unión íntima con Dios y de la unidad de todo el género humano» ${ }^{15}$-, vamos a comenzar recabando el estilo de sacerdocio que se desprende de esa mirada intensa que el Hijo posa sobre su Padre (cf. Jn 6, 46). No en vano, es a esta relación fundante entre las personas divinas a la que apela en la actualidad el magisterio de la Iglesia para profundizar en la comprensión de la raíz del ser y el estilo del quehacer específico del sacerdocio ministerial en el seno de la misma:

Nuestra identidad tiene su fuente última en la caridad del Padre. Con el sacerdocio ministerial, por la acción del Espíritu Santo, estamos unidos sacramentalmente al Hijo, enviado por el Padre como Sumo Sacerdote y buen Pastor. La vida y el ministerio del sacerdote son continuación de la vida y de la acción del mismo Cristo. Ésta es nuestra identidad, nuestra verdadera dignidad, la fuente de nuestra alegría, la certeza de nuestra vida ${ }^{16}$.

recibido esta comunión con Dios si su Verbo no hubiera entrado en comunión con nosotros haciéndose carne? Por eso pasó por todas las edades de la vida, haciendo así posible a todo hombre la comunión con Dios»: Irénée de Lyon, Contre les heresies. Dénonciation et réfutation de la gnose au nom menteur, Paris 2011, 366; lib. III, 18, 7.

13. M. Vilas, Ordesa, Barcelona 2018, 237.

14. J. Zumstein, El Evangelio según Juan (Jn 13-21), Salamanca 2016, vol. II, 238-242.

15. Concilio Vaticano II, Const. Lumen gentium, n. 1: AAS 57 (1965) 5.

16. Juan Pablo II, Pastores dabo vobis, n. 18: AAS 84 (1992) 685-686. Es cita del Mensaje de los Padres sinodales al Pueblo de Dios (28 octubre 1990), III: L'Osservatore Romano, ed. esp., 2 noviembre 1990, 12. También recogido en Congregación para el Clero, Directorio para el ministerio y la vida de los presbiteros, n. 3, Roma 2013, 20. 
Así pues, proponemos fijar la atención en la original reflexión que lleva a cabo el autor de la Carta a los Hebreos sobre el singular carácter de mediación que reconoce la fe de la primera comunidad cristiana en la vida y misión de Jesucristo. Hebreos es el único escrito del Nuevo Testamento que vincula de forma explícita la identidad filial de Cristo con el legítimo reconocimiento de su realización en la carne como ejercicio de un sacerdocio sumo y eterno.

\section{Carta a los Hebreos: el Sacerdocio de Cristo en el horizonte de SU HISTORIA FILIAL}

Teniendo en cuenta que tanto exégetas como historiadores de los orígenes cristianos coinciden en señalar cómo el Nuevo Testamento no adopta un lenguaje sacerdotal tal y como se emplea en la tradición hebrea para referirse a los ministros de la Iglesia ${ }^{17}$, se torna crucial explorar la respuesta a este interrogante: entonces, ¿en qué medida puede decirse que la cristología sacerdotal de la Carta a los Hebreos es una adquisición no ajena a la cristología del Nuevo Testamento, centrada fundamentalmente en torno a los títulos de Mesías, Señor, Salvador y, sobre todo, Hijo? No cabe duda de que en el Nuevo Testamento Jesús se presenta como el verdadero y único mediador entre Dios y los hombres (cf. Jn 14, 6; 1Tm 2, 5; Rm 5, 15-19) a quienes une y reconcilia (cf. Mt 9, 6; Lc 5, 24; 2Co 5, 14-20); y lo es en cuanto dotado de la plenitud de la humanidad (cf. 1Co 15,21) y la divinidad (cf. Col 2, 9; Rm 9, 5).

Volviendo al interrogante que plantea la cristología sacerdotal de Hebreos, a lo que nos interesa aproximarnos es al hecho de que cuando la primera Iglesia habla de sacerdocio (de Cristo, del creyente bautizado y del ministro ordenado) lo hace con un sentido profundamente propio (nuevo), no asimilable a la forma mentis que determina la categoría veterotestamentaria (y pagana) de sacerdocio ${ }^{18}$. De modo que es la especificidad de la mediación de Cristo-Hijo entre Dios y el hombre -su raíz en la paternidad divina y su realización filial en la existencia humana- la que funda la autoconciencia

17. Puede verse una síntesis esclarecedora y actualizada en: R. Penna, Un solo corpo. Laicità e sacerdocio nel cristianesimo delle origini, Torino 2020.

18. Dicho lo cual, cabe reconocer que el background del motivo sacerdotal que entra a formar parte de la tradición cristiana resulta bastante complejo. En este sentido, por ejemplo, no es posible obviar la influencia que la visión de la Carta a los Hebreos recibe de las tradiciones sacerdotales vigentes en la espiritualidad del judaísmo de la época del Segundo Templo. Véase al respecto: E. F. Mason, «You are a Priest Forever». Second Temple Jewish Messianism and the Priestly Christology of the Epistle to the Hebrews, Leiden-Boston 2008. 
sacramental y el desempeño ministerial de la Iglesia en continuidad con la mediación del Hijo, por quien «tenemos libre acceso al Padre en un mismo Espíritu» $(\mathrm{Ef} 2,18)^{19}$.

\section{a) La paternidad de Dios, la filiación de Jesús y la comunidad de los herederos}

El autor de Hebreos, en sintonía con la cristología del evangelio, exhorta a sus oyentes a considerar que la constatación creyente acerca del carácter mediador (sacerdotal) concierne propiamente a la identidad del Hijo, y se revela en la trayectoria de una historia personal concreta: la que ha vivido Jesús como Hijo que, a través de la experiencia de la carne, aprende y perfecciona su respuesta a la voluntad originante del Padre, logrando así que el resto de hijos puedan vislumbrar en su propia historia personal el camino que les conduce a la gloria ( $\mathrm{cf}$. $\mathrm{Hb} 2,10)^{20}$.

19. En este momento no es posible estudiar - pues sería objeto de una reflexión mucho más amplia- el proceso por el cual la tradición de la Iglesia llega a entender que la participación en la única y definitiva mediación salvífica de Cristo no sólo pasa por la identificación de la comunidad de los discípulos con el misterio pascual del Hijo mediante la profesión de fe y el sacramento del bautismo, sino que también, y al mismo tiempo, ha de ser significada por una consagración personal (ministro) de carácter específicamente sacerdotal vinculada a la identidad sacramental de la Iglesia. Creo que como punto de partida de esta reflexión habría que considerar la visión paulina del «nosotros», es decir, de la fraternidad que caracteriza a la comunidad de fe con la que el apóstol comparte su ministerio y a cuya luz entiende su capacitación personal-crística para el mismo. Pablo emplea a veces el léxico sacerdotal (Rm 1, 9: «Dios, a quien doy culto [latreúô] en mi espíritu, predicando el evangelio de su Hijo»; Rm 15, 15-16: «en virtud de la misión que Dios me ha confiado: ser para los gentiles ministro [leiturgós] de Cristo Jesús, ejerciendo el sagrado oficio del evangelio de Dios [hierourgoûnta tò euaggélion], para hacer de los gentiles una ofrenda agradable [hê prosforà tôn ethnôn], santificada por el Espíritu Santo»), pero no en el contexto de un ejercicio estrictamente cultual, sino más bien a propósito del ministerio apostólico como contribución al fortalecimiento de la dinámica de la vida cotidiana de la comunidad cristiana. Véase, por ejemplo: S. Guijarro, «El ministerio según 2 Co 2, 14-7, 4», en: G. Uribarri (ed.), El ser sacerdotal: fundamentos y dimensiones constitutivas, Madrid 2010, 63-79; R. Penna, Un solo corpo. Laicità e sacerdocio nel cristianesimo delle origini, 180-189.

20. En lo que sigue me inspiro fundamentalmente en la monografía de Amy L.B. Peeler, You Are my Son. The Family of God in the Epistle to the Hebrews, London-New York 2014. Remito a este estudio para una contextualización exhaustiva a la luz de la crítica especializada de la importancia que haya de concederse en la teología de Hebreos a la presentación de Jesus como Hijo. La verdad es que la panorámica de temas que pueden asumirse como preocupación-guía de la carta es muy amplia: ya sea desde el punto de vista teológico (la filiación de Cristo, el sumo sacerdocio de Cristo, la supremacía universal de Cristo, la finalidad de todo en Cristo, el concepto de Alianza, el dualismo entre mundo celestial y universo físico, la visión escatológica), o parenético (la vida cristiana como peregrinaje, la perseverancia en la fe post-apostólica, la asunción de la promesa de Dios, la misión de la comunidad cristiana en el mundo). Para una síntesis de estos aspectos y tener noticia de algunos de los comentaristas de habla inglesa que los tratan, véase: Bryan R. Dyer, «The 
Lo cierto es que, de principio a fin de la carta, a partir del hecho mismo de que Dios habla, el autor dibuja un penetrante retrato de la identidad de Dios como relación interpersonal. En efecto, al hablar-especifica el autor-Dios se dice «por medio del hijo» $(1,2)$, evocando así el lenguaje familiar como el preferido de Dios: se dice Padre a la luz de la relación con su Hijo Jesús ${ }^{21}$. Esta apertura da lugar a un discurso que se organiza en referencia contínua a la revelación de Dios como Padre, tanto en su diálogo con Jesús como con el hombre que ha creado a través de su habla; lo que permite al autor describir a un Dios particularmente íntimo y amoroso.

En efecto, el tema familiar introducido por la expresión «por medio del hijo» sigue apareciendo en momentos clave de la carta. La primera vez que se recoge en Hebreos el habla de Dios en primera persona, Él mismo declara su identidad paterna en la relación con su Hijo (1, 5-6). Antes de que el autor proclame la llamada divina de Jesús a ejercer un sacerdocio «a la manera de Melquisedec» $(5,10)$, Dios vuelve a recordar que su paternidad es la fuente de esa vocación sacerdotal de Jesús (5, 5-6). La primera vez que Dios se dirige de manera explícita al autor y a su audiencia, confirma su identidad «como hijos» (12, 5-6). Estos ejemplos apuntan a que el autor destaca y mantiene a lo largo de la carta la referencia a la paternidad de Dios y, a esta luz, mediante el vínculo íntimo entre la identidad divina (dimensión ontológica) y el carácter mediador (dimensión existencial) del Hijo, presenta a los destinatarios de la carta como aquellos a quienes Dios reconoce como su familia (hijos) y con quienes comparte sus bienes.

En efecto, el autor hace pivotar el lenguaje empleado a lo largo del escrito en torno a la palabra 'padre', con la que Dios mismo de presenta (1, 5 y 12, 9); dando cuenta así de la importancia que se concede a la referencia familiar ${ }^{22}$. Por otro lado, dado que al principio se define la paternidad de Dios ante todo a la luz de la filiación de Jesús, cada mención de Jesús invoca en lo sucesivo esta relación $(1,2.5 .8 ; 3,6 ; 4,14 ; 5,5.8 ; 6,6 ; 7,3.28 ; 10,29)$. Se alude a

Epistle to the Hebrews in Recent Research: Studies on the Author's identity, his Use of The Old Testament, and Theology», Journal of Greco-Roman Christianity and Judaism (2013) 104-131. Para comparar la confesión de la filiación divina de Jesús según Hebreos con la sensibilidad al respecto del resto de escritos post-paulinos del Nuevo Testamento, véase: J.D. Dunn, Christology in the Making. A New Testament Inquiry into the Origins of the Doctrine of the Incarnation, London 1992, 2 ed., 46-60.

21. Sobre el modo en que la cristología del Hijo de $\mathrm{Hb} 1$ se propone en continuidad con la fe de la primera comunidad cristiana y la paradoja que representa en relación con el monoteísmo judío, véase: David H. Wenkel, «The Paradox of High Christology in Hebrews 1», Biblica 99 (2018) 431-446.

22. Amy L. B. Peeler, You Are my Son, 46-51. 
la condición filial Jesús cuando se describe su condición como heredero de Dios a su diestra $(1,2,4 ; 8,1 ; 10,12 ; 12,2)$ y el contenido de dicha herencia $(1,2,3,13 ; 2,7-9 ; 5,9 ; 13,21)$. En esta línea, es la perenne relación con Dios que define la identidad del Hijo $(1,2 ; 5,5)$ la que proporciona el horizonte en que se entiende que Dios -como el padre que enseña y guía a su hijo- hace madurar al Hijo (mediante un camino de perfección en la experiencia de la carne: 5,$8 ; 7,28$ ) mediante la vocación que le ha sido encomendada por el Padre para alumbrar el camino a otros hijos-hermanos en todo el rango de la experiencia humana ${ }^{23}$.

De modo que el autor describe en los mismos términos filiales la relación que tienen con Dios todos aquellos a quienes se dirige y en quienes actúa la mediación del Hijo: son hijos de Dios (2, 10; 12, 5-8, 13-14), forman parte de la casa de Dios $(3,6)$ y son hermanos de Jesús $(2,11-12,17 ; 3,1,12 ; 10$, $19 ; 13,22)$; por tanto, también son objeto de la correccion de Dios $(12,5-11)$ mientras aguardan su herencia como hijos $(1,14 ; 6,17 ; 9,15 ; 11,40 ; 12,11$, 22-24, 28). Porque Dios perfecciona a su Hijo Jesús mediante la experiencia humana decisiva del sufrimiento y la muerte como vía a una vida plena (resurrección), permite que los testigos que pasan por dicha experiencia puedan reconocer su participación en el mismo destino: en Jesús superan el límite de la exclavitud y el miedo a la muerte $(2,15)$, les libera de todo pecado $(1,3 ; 2$, $17 ; 3,13,17 ; 5,1 ; 8,12 ; 9,26 ; 10,12,17)$ y les concede la esperanza que les es propia a quienes ostentan la condición de hijos de $\operatorname{Dios}^{24}$.

En suma, es la imagen de la familia la que sirve al autor para presentar la relación íntima que mantienen entre sí los actores principales de la carta (Dios, Jesús y la comunidad de los discípulos: entre quienes se cuenta el

23. «De hecho, mientras Hebreos escribe varias veces que Jesús 'llega a ser' Sumo Sacerdote (el uso de gígnomai en 2,$17 ; 5,5 ; 6,20$ ), nunca afirma que Jesús 'haya llegado a ser' Hijo»: R. Penna, I ritratti originali di Gesù. Inizi e sviluppi della cristologia neotestamentaria. Gli sviluppi, Milano 1999, vol. II, 285.

24. «Aunque Hebreos nunca se refiere explícitamente a su audiencia con el término 'iglesia' (ekklēsia), y más allá de 9, 28 y 10, 37 apenas habla sobre la parusía, presupone una intensa eclesiología y escatología que se pueden sintetizar en estos términos: la iglesia es el pueblo escatológico de Dios porque vive en los últimos días en los que Dios ha hablado por medio de su Hijo. Como pueblo escatológico de Dios, la iglesia es un pueblo peregrino en busca de una ciudad definitiva donde encontrará el reposo que el propio Jesús, 'pionero' de su salvación $(2,10)$ y ‘consumador' de su fe $(12,2)$, ya goza. De modo que, así como la soteriología de Hebreos presupone una cristología que presenta a Jesús como Hijo eterno de Dios y sumo sacerdote según el orden de Melquisedec, su eclesiología presupone una escatología que busca la ciudad eterna donde el pueblo de Dios que peregrina disfrutará del reposo del Sabbat divino»: F. J. Matera, «The Theology of the Epistle to the Hebrews», en: E. MasonK. McCruden (eds.), Reading the Epistle to the Hebrews. A Resource for Students, Atlanta (GA) 2011, 204. 
propio autor y sus destinatarios); y, en definitiva, es la imagen que permite a la carta hacerse eco del anuncio de la fe apostólica sobre la continuidad de sentido entre teología (paternidad), cristología (filiación), antropología y soteriología (adopción filial), y eclesiología (vida y ejercicio de la herenciacondición mediadora del Hijo $)^{25}$.

\section{b) Caridad filial y sumo sacerdocio}

Lo que ahora deseo destacar-siempre en alusión a la teología de la filiación presente en Hebreos- es que el anuncio y la expresión creyente de la mediación única y definitiva que representa la vida de Jesús como oferta de sí mismo -carne y sangre $(2,14)$ - por la salvación escatológica del mundo y la historia de los hombres -todo $(2,8)$-, remite a la escucha de lo que el propio Dios dice de Jesús: que forma parte de Sí mismo como tú filial $(1,5)$, y que ha estado dispuesto a dejarse perfeccionar según la cadencia amorosa que es propia de la relación del Padre con el Hijo en cuanto configurada como verdadero nosotros, es decir, como espacio de comunión abierto a incorporar plenamente como hijos a los hombres que Dios ha creado $(2,6-8)^{26}$. En efecto, la identidad de Jesús como Hijo de Dios es también, sin ocultar la paradoja que ello supone, la del hombre Jesús que «tiende una mano a la descendencia de Abrahán», es decir, a todos los hombres $(2,16)$, portadores de la vocación de hijos; a quienes, en consecuencia, «no se avergüenza de llamar hermanos» $(2,11)$. Esta es la premisa con la que el autor se dirige enseguida a presentar a Jesús como «sumo sacerdote misericordioso y fiel» $(2,17)$. Misericordioso, porque «se asemeja en todo a sus hermanos» $(2,17)$ y puede «compadecerse de nuestras debilidades» $(4,15)$; fiel, en cuando plenamente consagrado a mediar por sus hermanos ante Dios porque ha pasado por su misma «tentación» $(2,18)$ y «ha sido probado en todo, como nosotros, menos en el pecado» $(4,15)^{27}$.

25. S. Guijarro, «La cristología neotestamentaria de la filiación y la teología trinitaria», Teología y Vida 60 (2019) 496.

26. Puede decirse, en suma, que la carta concentra su principal interés en ahondar en la vinculación entre la razón de ser divino-filial y la hondura de la realización existencial de esta mediación sacerdotal de Cristo, que carece de parangón tanto en el mundo judío como en el pagano (Y. Congar, Sacerdocio y laicado, 85-93).

27. La perspectiva de la solidaridad es la que permite incluir la realidad del pecado en el «todo» de la semejanza de Jesús con sus hermanos. Jesús asume en sí las consecuencias de la contradicción que opera el pecado en el ser del hombre (12, 2-3). De manera que, la perfección del sacerdocio de Jesús $(4,15 ; 7,26)$ «lejos de abrir un foso entre Cristo y nosotros, convierte nuestras pruebas y debilidades en el lugar privilegiado de nuestro encuentro con él, y no solamente con él, sino con Dios mismo, gracias a él»: A. Vanhoye, Sacerdotes antiguos, sacerdote nuevo según el Nuevo Testamento, Salamanca 1984, 126. Comentando la expresión de Heb 4, 15, señala Cullmann que «esta declaración de la Carta a los Hebreos que va 
El autor de Hebreos señala que es a Dios Padre en su adhesión a Jesús como Hijo a quien hay que reconocer como fuente de la autoridad sacerdotal de Jesús y, por tanto, como inspiración de la novedad con que éste expresa en sí y propicia en los demás hombres la confianza en su dignidad de hijos de Dios: no mediante una correspondencia con la voluntad de Dios fruto de un esfuerzo estrictamente propio, sino a través del amor compasivo, generoso, fiel, misericordioso y liberador que nace de reconocerse amado por Dios de esa misma manera. Es cierto que «todo sumo sacerdote está tomado de entre los hombres y constituido a favor de los hombres en lo que se refiere a Dios» $(5,1)$-que es el único que concede esa dignidad y honor-, empero en el caso de Cristo su vocación como mediador entre Dios y los hombres procede del Dios que se expresa como su Padre; es decir, procede de Aquel que lo reconoce como su hijo $(5,5)^{28}$, cuya vocación es la de santificar a muchos otros hijos con los que comparte «el mismo origen» $\mathrm{y}$ «por eso no se avergüenza de llamar hermanos» $(2,11)$. De modo que, en rigor y a diferencia de lo prescrito en el Antiguo Testamento, Jesús no ha sido consagrado -en el sentido de separado de- «a favor de Dios» (cf. Ex 28, 1; Lv 21, 10-23), sino más bien a favor de los hombres: en el sentido de separado para unirse completamente a todos aquellos que Dios quiere atraer hacia sí. Cabe reconocer que,

si en el Antiguo Testamento el mayor problema consistía en asegurar la comunicación entre el sacerdote y Dios [...] era preciso de alguna manera olvidarse de que el sacerdote era solamente un hombre como los demás, miserable y pecador por el mismo título que sus hermanos, ya que esto lo hacía indigno de presentarse ante Dios. Por eso se insistía tanto en los ritos de separación [...] en el caso de Cristo la relación con Dios no presentaba ningún tipo de dificultades ya que Cristo era «el Hijo de Dios» $(4,14)$, «resplandor de su gloria e impronta de su ser» $(1,3)$. Lo que se trataba de establecer era más bien su relación con los hombres. Por este lado la solidaridad no estaba ni mucho menos adquirida de antemano [...] no era un dato primario sino una realización por crear con vistas a una misión que no podía realizarse sin ella ${ }^{29}$.

más allá del testimonio de los sinópticos, es tal vez la afirmación más osada de todo el Nuevo Testamento sobre el carácter absolutamente humano de Jesús. Esta observación breve, pero cargada de tremendas consecuencias, arroja una luz particular sobre la vida de Jesús y dirige nuestra atención hacia aspectos de esa vida que no conocemos y que el autor de la Carta a los Hebreos seguramente tampoco conocía. Tenemos que ser precavidos, no buscando en ella un tema de novela, porque nada concreto sabemos de estas tentaciones kata panta ('en todo'). Lo esencial, desde el punto de vista cristológico, es que Jesús fue tentado en todas las cosas como nosotros mismos, pero que no ha sucumbido»: O. Cullmann, Cristología del Nuevo Testamento, Salamanca 1998, 152.

28. Amy L.B. Peeler, You are my Son, 115-118.

29. A. Vanhoye, Sacerdotes antiguos, sacerdote nuevo según el Nuevo Testamento, 99. 
Y así, en orden a operar una vinculación viva entre Dios y los hombres, el autor de Hebreos anuncia que la muerte de Jesús no consiste en un acto de satisfacción que Dios reclama, cuanto de «liberación» del hombre que teme a la muerte y «está de por vida sometido a esclavitud» $(2,15)$. Puede entenderse entonces que Jesús sea el mediador de la alianza que se echa de menos en el Antiguo Testamento ( Jb 9, 33: «si al menos hubiera un mediador que pusiera su mano entre los dos»), pues en verdad es capaz de renovarla $(7,22 ; 8,6 ; 9$, $15 ; 12,24)$ al ejercer un tipo de mediación que no es la de carácter religioso que conoce y practica Israel bajo el esquema de la Ley $(7,11$ : «a la manera de Aarón»). Es así como entra en escena la original individuación que hace el autor de Hebreos de la misteriosa figura de Melquisedec como prototipo de un sacerdocio «cambiado» $(7,12)$, por el que «queda abrogado el orden precedente, por razón de su ineficacia e inutilidad» $(7,18)$.

En efecto, Jesús es sacerdote «a la manera de Melquisedec» $(5,7,10 ; 7$, $11,17)$, es decir, ejerce una mediación que puede llamarse definitiva $(7,22$, 24, 28: «para la eternidad») o más allá de cualquier parámetro de institucionalidad terrena; fundamentalmente porque el mediador «está siempre vivo» $(7,25)$, no sometido al ritmo del tiempo y la necesidad que marca éste de repetir rituales y sacrificios que garanticen la continuidad de la mediación ${ }^{30}$. Pero, como ya hemos notado, esta acreditación de «Jesús, el Hijo de Dios» como «sumo sacerdote que penetró los cielos» $(4,14)$ no es la de aquel que logra «la gloria de la ambición satisfecha», sino la de quien recibe la «gloria del amor generoso ${ }^{31}$. Por ello, todos los que han experimentado su amor

30. En el Nuevo Testamento sólo la Carta a los Hebreos reclama la figura de Melquisedec, que en el judaísmo de los siglos I-II llegó a adquirir una importancia notable. Al evocar su resonancia en los manuscritos de la comunidad de Qumrán -donde se presenta a Melquisedec como sumo sacerdote que, unido a la intervención angélica en la batalla escatológica de las fuerzas divinas frente a Belial, trae consigo la salvación en el Día del Juicio-, Margaret Barker pone de relieve cómo el sacerdocio de Melquisedec adquiere en la cristología de Hebreos tintes semejantes, si bien la referencia inmediata con que la sensibilidad cristiana lo reclama es el misterio de la Pascua de Cristo: «Según algunas evidencias, la Carta a los Hebreos participa en la creencia de que el sumo sacerdote Melquisedec había resucitado, es decir, que vivía una vida celestial en lugar de la propia de esta tierra. Melquisedec carece de ascendencia $(\mathrm{Hb} 7,3)$ y así se asemeja al Hijo de Dios. El contraste en este capítulo de la carta es entre la ascendencia según la carne, que era el requisito para el sacerdocio de Aarón, y 'el poder de una vida indestructible', que es lo que caracteriza el sacerdocio de Melquisedec. Esto sugiere que ser elevado, lo que se afirma dos veces de Melquisedec en $\mathrm{Hb} 7$, no debe entenderse como el que ha sido 'ensalzado a un oficio superior' sino como el 'resucitado', esto es, aquel que ha sido hecho sumo sacerdote en virtud de una vida indestructible (los verbos son anistasthai, v. 11; anistatai, versículo 15)»: M. Barker, The Great High Priest. The Temple roots of Christian Liturgy, London-New York 2004, 113. Véase también, A. Vanhoye, Epistola agli Ebrei. "Un sacerdote diverso», Bologna 2010, 151.

31. A. Vanhoye, Sacerdotes antiguos, sacerdote nuevo según el Nuevo Testamento, 124. 
pueden así fundar en la extraordinaria dignidad gloriosa de Cristo sacerdote la invitación a la fe en la eficacia de su mediación (4, 16: «acerquémonos, por tanto, al trono de gracia, a fin de alcanzar misericordia y encontrar el favor de un auxilio oportuno»).

La carta incluye una expresión -tal vez la más conocida de la misma-en que el autor evoca el acontecer de la pasión y resurrección de Jesús para describir (hasta donde le es posible al espectador) la hondura del drama acontecido en la experiencia vital del Hijo: en ella se relaciona la trascendencia gloriosa de la existencia divina con la finitud dolorosa de la humana y, precisamente por ello, se puede reconocer a Jesús como mediador definitivo para que otros logren (asumiendo en confianza filial esa misma vulnerabilidad pascual) su más alta posibilidad de ser:

Cristo, después de haber ofrecido en los días de su vida mortal ruegos y súplicas con poderoso clamor y lágrimas al que podía salvarlo de la muerte, fue escuchado por su actitud reverente. Y, aunque era Hijo, aprendió la obediencia a través del sufrimiento. De este modo, alcanzada la perfección, se convirtió en causa de salvación eterna para todos los que le obedecen $(5,7-9)$.

Sin duda esto evidencia que Jesús realiza el oficio sacerdotal en un registro muy distinto al ritual, esto es, el personal ${ }^{32}$. Jesús no ofrece una víctima ajena, sino la dolorosa vivencia de sí como total donación al otro (hasta la muerte). Haciendo resonar el tono de la oración en Getsemaní (cf. Mc 14, 33-36) ${ }^{33}$, el autor de Hebreos presenta la súplica de salvación de Jesús como un verdadero acto litúrgico ante la voluntad del Padre; una liturgia que no responde a un esquema de oración ya prefijado sino a un dinamismo de tipo pascual: al paso por la realización en la existencia (de la carne) de la relación filial constitutiva; la que define constantemente la conciencia de Jesús como respuesta al amor del Padre ${ }^{34}$. Dicho en otras palabras: aprender la obediencia a través del sufrimiento,

32. «El culto es radicalizado y enquiciado en el orden personal. La libertad, vivida en obediencia amorosa a Dios y en servicio generoso a los hombres, es el verdadero sacrificio [...] Esta ofrenda de libertad abarcó toda su vida. Con ella aprendió en humanidad la filiación por la forma suprema de aprendizaje: la pasión en el sentido de sufrimiento pathein = mathein $(5,8) »$ : O. González de Cardedal, Fundamentos de cristología. Meta y misterio, Madrid 2006, vol. II, 525-526.

33. O. Cullmann, Cristología del Nuevo Testamento, 153.

34. «El que ora -escribe Vanhoye-se prohíbe a sí mismo decidir por sí solo y liberarse a sí mismo. Se abre a la acción de Dios y consiente en la relación interpersonal [...] El objeto de la oración resulta entonces secundario. Lo que importa ante todo es la relación con Dios. En los evangelios, después de haber implorado su liberación, Jesús añade: 'Pero no sea como yo quiero, sino como quieras tú' (Mt 26, 39). Y lo que parecía primero una cláusula sobreañadida 
significa que Jesús ha tenido que reconocer lentamente los ritmos y leyes de su existencia, aprender a reconocer a Dios como su Padre, a reconocerse reconocido por este Padre, incluso y sobre todo en el momento del fracaso. Ha aprendido a obedecer hasta descubrirse representante con-digno, con-genial, con-génito de este Padre. Tal vez, por vez primera, ese descubrimiento se hace patente en aquella parábola tan colorida y polivalente del llamado hijo pródigo o padre misericordioso (en Lc 15) ${ }^{35}$.

La expresión de los v. 7-8, precisamente, se refiere al oferente como a aquel cuya vida pasa por una profunda transformación -un proceso, un tener que hacerse...- a través de un sufrimiento (o despojo de sí mismo, cf. Flp 2, 6-8) que tiene el carácter de un aprendizaje vital en cuanto se lee a la luz de la relación de escucha mutua entre el Padre y el Hijo ${ }^{36}$. Una transformación, visible en la humanidad del Hijo, que podemos considerar personal, o sea, realmente existencial, no ritual. Pues, en efecto, el estilo del diálogo entre el Hijo (ruego, súplica confiada) y el Padre (escucha deferente), es signo de una relación que, como toda genuina relación entre personas, está marcada por una distancia misteriosa, no exenta de una soledad dolorosa (lágrimas), que es la que permite sustanciar la identidad íntegra (perfecta) de quienes se relacionan ${ }^{37}$.

Así pues, Hebreos proclama la mediación sacerdotal de Jesús en línea de conformidad con la constante fe de la primera Iglesia en la filiación divina como un rasgo distintivo de la propia identidad de Jesús: en su biografía histórica muestra que es desde la relación (conciencia interior de su unidad volitiva, que se vuelve cognitiva, con el Padre) y vive para la relación (realización

se va convirtiendo poco a poco en la petición principal: 'Padre mío..., hágase tu voluntad' (Mt $26,42)$. Así es como la oración transforma el deseo que se va modelando sobre la voluntad del Padre, sea cual sea, ya que el que ora aspira ante todo a la unión de sus voluntades en el amor»: A. Vanhoye, Sacerdotes antiguos, sacerdote nuevo según el Nuevo Testamento, 141.

35. E. Salmann, Il respiro della benedizione. Spiragli per un ministero vivibile, Assisi 2010,56 .

36. El autor emplea en ambos versículos una variante del verbo akoúo, que se emplea en el griego profano y en el de los LXX con el significado de escuchar a, responder y obedecer. W. Mundle, «akoúo (oír)» en: L. Coenen - E. Beyreuther - H. Bietenhard (dirs.), Diccionario Teológico del Nuevo Testamento, Salamanca 1993, 3 ed., vol. III, 203-209.

37. En línea con la sensibilidad de la cristología contemporánea hacia el testimonio neotestamentario sobre la experiencia del Jesús hombre, Olegario González trata de ahondar en el sentido de la soledad de Jesús en Getsemaní, que es la que resuena en esta expresión de Hebreos: «Lo que encontramos en la soledad de Jesús llegado a Getsemaní es la penetración en la entraña de lo que es la libertad humana, participación de la infinitud divina con capacidad para acoger a Dios, rechazarlo o declararlo inexistente [...] Dios no es causante de la agonía de Jesús, sino asombrado espectador de ella, paciente acompañante del Hijo y de los hijos»: O. González de Cardedal, Jesucristo. Soledad y compañia, Sígueme, Salamanca 2016, 86-87. 
vital en apertura a la voluntad del Padre $)^{38}$. No en vano, como también hemos señalado en la reflexión de Hebreos, según el testimonio evangélico Jesús no sólo atrae a los discípulos hacia sí (cf. Mc 3, 13-14; Mt 4, 18-22; Lc 5, 10-11), sino que los orienta en la dirección de una relación ulterior, con la paternidad de Dios-Padre y la comunión en el Espíritu (cf. especialmente Jn 17). Es decir, quien es Hijo conduce al discípulo a esclarecer su propia conciencia filial divina enseñándoles a mirar, invocar y vivir ante Dios con los ojos del Hijo (cf. Lc 22, 61), la plegaria del Hijo (cf. Lc 11, 1-4) y la entrega vital del Hijo (cf. Lc 22, 19-20). Puede decirse, por tanto, que en las notas esenciales de la caridad filial de Jesús se abre paso la caracterización de la caridad pastoral del discípulo, enviado en su nombre: permanencia en la libertad que se aprende en el discernimiento de la voluntad del Padre, y conforma la vida como servicio de amor a la historia particular de cada hombre ${ }^{39}$.

\section{TRANSICIÓN}

Como manifiestaba hace unos años un joven sacerdote, miembro de la Iglesia católica de Irlanda, particularmente golpeada por la realidad de los abusos sexuales del clero, «para afrontar esta época que cambia rápidamente, necesitamos, ciertamente, mucho más que meras estrategias de management. ¿No es momento de que profundicemos y reflexionemos sobre el corazón de nuestra misión como sacerdotes, discípulos de Jesucristo?» ${ }^{40}$.

Pues bien, el ánimo de este estudio no es otro que el de atender esta invitación a asumir el tiempo presente como contexto para la actualización de la identidad y misión del ministerio sacerdotal. Para ello, hemos tomado como punto de partida la reflexión de la Carta a los Hebreos: el único escrito del Nuevo Testamento que connota la identidad filial y la obra redentora de Cristo con categorías directamente sacerdotales. El autor de la carta afirma que el sacerdocio del Antiguo Testamento adquiere en el sumo sacerdote que es Cristo su cumplimiento definitivo, porque exhibe dos diferencias esenciales: si los sacerdotes judíos ofrecían una víctima distinta de sí mismos, Cristo ofrece la realidad de su propia persona al vivir en el mundo su identidad divina como Hijo en constante sacrificio a la voluntad salvífica del Padre para con el resto

38. J. Ratzinger, Jesús de Nazaret, en: Id., Obras Completas, Madrid 2015, vol. VI/1, 365-372.

39. H.U. von Balthasar, «Der Priester im Neuen Testament. Eine Ergänzung», Geist und Leben 43 (1970) 39-45.

40. P. Dempsey, «Being a Priest in Ireland Today. A Young Priest's View», The Furrow $12(2010) 670$. 
de sus hijos; además, mientras el sacerdote judío realizaba su oficio sacerdotal alejándose del mundo de los hombres para entrar en el de Dios, Cristo es sacerdote radicando su identidad divina de Hijo en la conciencia humana de sí como don para el otro; haciendo suyas, por tanto, las expectativas de logro y las dificultades vitales que son propias de dicha conciencia no sólo en cuanto se auto-reconoce como procedente de otro, sino en cuanto despliega dicha alteridad de origen en su experiencia histórica y su deseo de plenitud ${ }^{41}$.

Teniendo en cuenta este horizonte, en la continuación de este estudio veremos que tanto la sensibilidad de la eclesiología del Concilio Vaticano II en torno al trasfondo de la relación entre sacerdocio común de los fieles y sacerdocio ministerial, como la del magisterio contemporáneo acerca de la teología de éste último, insisten en la genuina marca cristológica que identifica la vida cristiana como mediación salvífica en cuanto radicada en la voluntad de Dios Padre; es decir, insisten en la relación filial que plantea el evangelio entre antropología y teología.

En la experiencia vital de Jesús la filiación cristiana - tanto para el bautizado como para el ministro consagrado- se presenta en su doble carácter de don divino y aprendizaje humano. Así pues, ser hijo solo es posible a través de un contacto personal, vivo y concorde con la lógica de Jesús, «que es la lógica del mediador, es la lógica de despojarse de sí mismo» ${ }^{42}$. Una lógica, en suma, que no afecta sólo ni principalmente a la forma o desempeño visible de la vivencia filial en la comunidad cristiana, sino a la propia configuración interior de la vida personal junto a los hermanos como relación amorosa con Dios Padre.

Al margen de esta configuración, la caridad pastoral del sacerdote que propone la teología del ministerio se convierte en una mera falsilla teórica; y no en el eje de la totalidad de su proyecto de vida. Dicho en primer persona: para asimilar el modo en que Él me ama he de conocer y hacer crecer el talento de las propias virtudes como espacio carismático, enfrentando, a la vez, la pobreza, la debilidad y los miedos que paralizan mi vida; es decir, todos aquellos espacios vitales en que prefiero mi seguridad (Mt 26, 39: «Padre mío, si es posible, que pase de mí este cáliz») a confiar en la inseguridad de la relación con el otro (Mt 11, 28: «Venid a mí todos los que estáis cansados y agobiados, y yo os aliviaré»).

41. H. Schürmann, El destino de Jesús: su vida y su muerte, Salamanca 2003, 267-301.

42. Tomo la expresión de una homilía pronunciada por el Papa Francisco en presencia de los seminaristas y formadores del Seminario Mayor de Roma: «Homilía en la capilla de la Domus Sanctae Marthae» (9 de diciembre de 2016). <https://www.vatican.va/content/ francesco/es/cotidie/2016/documents/papa-francesco-cotidie_20161209_sacerdotes-autenticos.html>. [Consulta: 1 jul. 2021] 


\section{BIBLIOGRAFÍA}

Balthasar, H.U. von, «Der Priester im Neuen Testament. Eine Ergänzung», Geist und Leben 43 (1970) 39-45.

Barker, M., The Great High Priest. The Temple roots of Christian Liturgy, London-New York 2004.

Benedicto XVI, Carta Enc. Caritas in veritate, AAS 101 (2009) 641-709.

Buber, M., Yo y Tú y otros ensayos, Buenos Aires 2013, 2 ed.

Comisión Teológica Internacional, La reciprocidad entre fe y sacramentos en la economía sacramental, Roma 2021.

Concilio Vaticano II, Const. Gaudium et spes, AAS 58 (1966) 1025-1120.

Concilio Vaticano II, Const. Lumen gentium, AAS 57 (1965) 5-75.

Congar, Y., Sacerdocio y laicado, Barcelona 1964.

Cullmann, O., Cristología del Nuevo Testamento, Salamanca 1998.

Dempsey, P., «Being a Priest in Ireland Today. A Young Priest's View», The Furrow 12 (2010) 667-676.

Dunn, J.D., Christology in the Making. A New Testament Inquiry into the Origins of the Doctrine of the Incarnation, London 1992, 2 ed.

Dyer, B. R., "The Epistle to the Hebrews in Recent Research: Studies on the Author's identity, his Use of The Old Testament, and Theology», Journal of Greco-Roman Christianity and Judaism (2013) 104-131.

Ebner, F., La realtà di Cristo, Brescia 2017.

Francisco, Evangelii gaudium, AAS 105 (2013) 1020-1137.

González de Cardedal, O., Fundamentos de cristología. Meta y misterio, Madrid 2006, vol. II.

González de Cardedal, O., Jesucristo. Soledad y compañía, Salamanca 2016.

Guijarro, S., «El ministerio según 2 Co 2, 14-7, 4», en: G. Uribarri (ed.), El ser sacerdotal: fundamentos y dimensiones constitutivas, Madrid 2010, 63-79.

Guijarro, S., «La cristología neotestamentaria de la filiación y la teología trinitaria», Teología y Vida 60 (2019) 475-496. DOI: 10.4067/S004934492019000400475

Irénée de Lyon, Contre les heresies. Dénonciation et réfutation de la gnose au nom menteur, Paris 2011.

Juan Pablo II, Carta Enc. Dominum et vivificantem, AAS 78 (1986) 809-900. Juan Pablo II, Exh. Apost. Post. Pastores dabo vobis, AAS 84 (1992) 657-804. Koch, K., La Iglesia de Dios. Comunión en el misterio de la fe, Santander 2015. Mason, E. F., «You are a Priest Forever». Second Temple Jewish Messianism and the Priestly Christology of the Epistle to the Hebrews, Leiden 2008. 
Matera, F. J., «The Theology of the Epistle to the Hebrews», en: E. Mason $\mathrm{K}$. McCruden (eds.), Reading the Epistle to the Hebrews. A Resource for Students, Atlanta (GA) 2011, 189-208.

Mundle, W., «akoúo (oír)» en: L. Coenen - E. Beyreuther - H. Bietenhard (dirs.), Diccionario Teológico del Nuevo Testamento, Salamanca 1993, 3 ed., vol. III, 203-209.

Peeler, Amy L.B., You Are my Son. The Family of God in the Epistle to the Hebrews, London-New York 2014.

Penna, R., I ritratti originali di Gesù. Inizi e sviluppi della cristologia neotestamentaria. Gli sviluppi, Milano 1999, vol. II.

Penna, R., Un solo corpo. Laicità e sacerdocio nel cristianesimo delle origini, Torino 2020.

Ratzinger, J., Jesús de Nazaret, en: Obras Completas, Madrid 2015, vol. VI/1.

Salmann, E., Il respiro della benedizione. Spiragli per un ministero vivibile, Assisi 2010.

Scholtus, R. «The Formation of Priests Today: Cultural and Social Challenges of Priestly Formation in Europe», Seminary Journal 19 (2013) 18-21.

Schürmann, H., El destino de Jesús: su vida y su muerte, Salamanca 2003.

Taylor, Ch., Las fuentes del yo. La construcción de la identidad moderna, Barcelona 2006.

Tenace, M., «La vocazione dell'uomo nuovo. Il senso della vita nuova accolta nel battesimo», en: P. Martinelli (a cura di), Custodi dello Stupore. La vita consacrata: Vangelo, profezia e speranza, Milano 2017, 221-240.

Vanhoye, A., Sacerdotes antiguos, sacerdote nuevo según el Nuevo Testamento, Salamanca 1984.

Vanhoye, A., Epistola agli Ebrei. «Un sacerdote diverso», Bologna 2010.

Vilas, M., Ordesa, Barcelona 2018.

Wenkel, David H., «The Paradox of High Christology in Hebrews 1», Biblica 99 (2018) 431-446. DOI: 10.2143/BIB.99.3.3285370

Zahavi, D., Self and Other. Exploring Subjectivity, Empathy, and Shame, Oxford 2014.

Zumstein, J., El Evangelio según Juan (Jn 13-21), Salamanca 2016. 